\title{
Motor Condition Monitoring Based on Time-Frequency Analysis of Stator Current Signal
}

\author{
Hakan Çalış and Hüseyin Fidan
}

\begin{abstract}
Induction motors are the most widely ysed type of motor in industry. Condition monitoring is crucial for the machine health. Whole system can be out of service when the motors are out of order. The correct diagnosis of beginning of the faults is very important for the system in which electricity motors are used in. Most of the motor failures occur due to the bearing faults. The reason of the fault is recognized by obtained information regarding to the signals from motors. The currently used Fourier transformation techniques fail to provide insight to the frequency analysis so it leads to apply time-frequency analysis including wavelet transform in the important field of signal analysis. Using only time domain or frequency domain restrict the analysis result. Especially, application of wavelet transformation to the non-stationary signals for getting frequency and time information at the same time gives excellent results. Discrete wavelet transformation that is a multi resolution algorithm analyses the signal by separating the signal into frequency components. The three phase motor currents and vibration data are obtained using four poles induction motor with size of $1 \mathrm{Hp}$. Then, the whole data set regarding to the healthy and faulty conditions are saved in a computer by digitizing using a data acquisition card. The sampled signals from experimental system are analyzed by using discrete wavelet transformation and motor bearing faults have been diagnosed. Ball and inner race faults are recognized by analyzing current signal information. Besides, the outer race fault has been found at the beginning stage.
\end{abstract}

Index Terms-Bearing faults, induction motor, motor faults, Wavelet transformation, condition monitoring.

\section{INTRODUCTION}

Condition monitoring (CM) of induction motors traditionally involves vibration measurement to detect mechanical failures, and steady state stator current measurements to determine electrical faults. In vibration analysis, there are some disadvantages such as the influence of the transmission path, the effect of certain resonance frequencies on the vibration signal and mechanical connection of the transducer. Therefore, recent studies are focusing on motor signature current analysis (MSCA) to detect mechanical faults without utilizing any additional sensor [1], [2].

The monitoring and analysis of motor current provide an indirect method of determining mechanical faults since it

Manuscript received September 5, 2014; revised October 30, 2014. This work was supported by Suleyman Demirel University Scientific Research Projects.

Hakan Çalış is with the Suleyman Demirel University, Department of Electrical-Electronics Engineering, Isparta, Turkey (e-mail: hakancalis@sdu.edu.tr).

Hüseyin Fidan is with the Mehmet Akif Ersoy University, Bucak Emin Gulmez Technical Sciences and Vocational School, Department of Computer Technology and Progr. Education, Burdur, Turkey (e-mail: hfidan@mehmetakif.edu.tr). does not require physical access to motor. The motor itself is used as a transducer to identify any change. Therefore, it is an attractive method. Considerable efforts have been put into detection of air-gap eccentricity and broken rotor bars [3]. One of the surveys made by EPRI in 1985 concerning the 7500 motor failures has showed that $41 \%$ of the faults are due to bearing faults [3]. However, it is still required to do research on the detection of mechanical faults on the use of MSCA compare to other faults. That is the main motivation for this work, and there is a demanding challenge to detect other common mechanical faults by MSCA. It is necessary to have a sensorless diagnostic monitoring system to detect the problems and thus enable a repair to be carried out at a convenient time to avoid disruption to production requirements.

The traditional approaches to detect bearing problems are vibration and temperature monitoring. For the localized bearing defects on outer race, inner race, cage and rolling element are monitored by calculation of frequency components according to the dimensions of bearing and rotor speed. These bearing defect frequency (BDF) components depend on the location of the fault and appear as impact pulses. They are usually in the frequency interval up to maximum 30 times rotor speed.

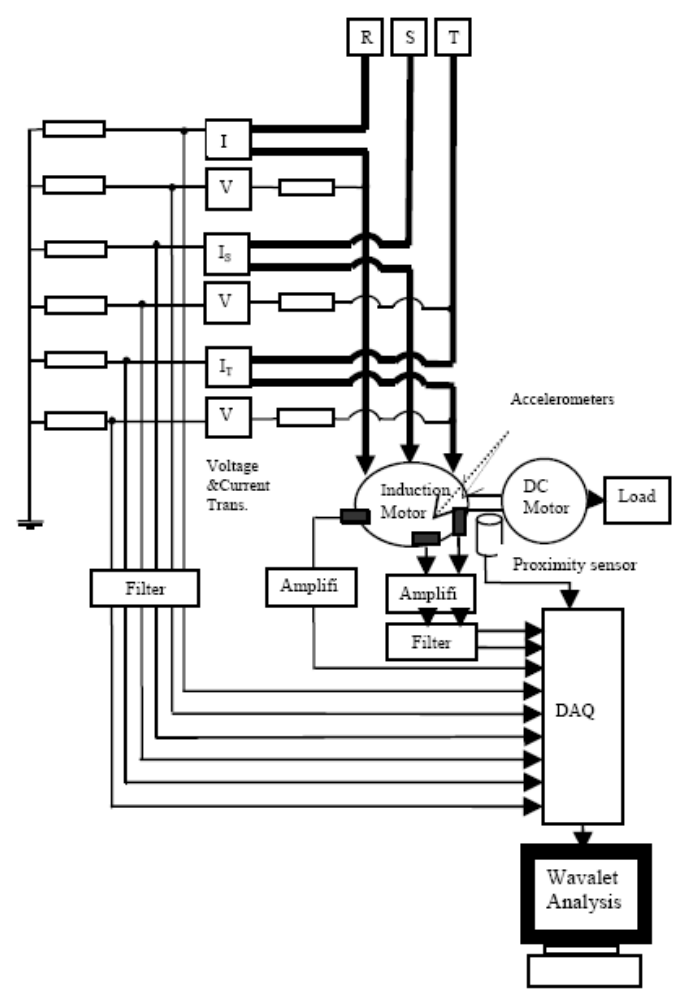

Fig. 1. Block diagram of the experimental circuit.

Wavelet transforms are used for analyzing starting 
ycurrents [4]. In the paper, mechanical faults are detected through the transients they cause in the stator current of the machine [5]. In addition, Bae and et al showed the usage of wavelet analysis to detect mechanical faults even in a very small size motor [6]. The authors are used wavelet algorithm for bearing fault detection to discriminate between multi machine faults [7].

In this study, the most common mechanical problem in electrical motor; bearing failure is investigated experimentally using vibration and motor current signal analysis techniques.

\section{SignAl ANAlysis AND DATA ACQUiSition SySTEM}

The block diagram of the experimental circuit for the analyzing of the motor current signal is shown below in Fig. 1.

Three phases of line voltages (by voltage sensors LEM CV 3-1000), and line currents (by Hall effect typed current sensors) and accelerometer signals are digitized simultaneously and recorded using a data acquisition card. Data segmentation and ensemble smoothing procedure are used to increase the signal to noise ratio. The motor used for the tests is a three phase squirrel cage induction motor. Its specifications are given in Table I.

TABLE I: SPECIFICATIONS OF TEST MOTOR

\begin{tabular}{|l|l|}
\hline Brand & Volt Elektrik \\
\hline Power (Hp/kW) & $1 \mathrm{Hp} / 0.75$ \\
\hline Voltage (V) & 380 \\
\hline Current (A) & 2,1 \\
\hline Speed (rpm) & 1370 \\
\hline Power Factor & 0,72 \\
\hline Efficiency & $73 \%$ \\
\hline Torque (Nm) & 5,2 \\
\hline Number of Rotor Slot & 22 \\
\hline Number of Stator Slot & 24 \\
\hline Bearing Type & ORS 6204 \\
\hline
\end{tabular}

The bearing fault was introduced in three steps in the test rig. The last point is representing an extreme amount of fault. Simulated faults are artificial contamination, thermal aging, and no lubrication faults (see Fig. 2).

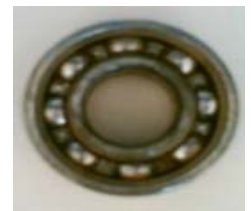

Fig. 2. A view of artificially introduced bearing fault.

On test motor there are two single rowed radial bearings (type 6204 on the non-drive end and 6204 on the drive end) (see Table II for more details).

TABLE II: TECHNICAL DETAILS OF BEARING

\begin{tabular}{|l|l|}
\hline Bearing No & $6204 \mathrm{ZZ}$ \\
\hline Number of Balls & 8 \\
\hline Diameter of Balls & $7,938 \mathrm{~mm}$ \\
\hline Diameter of inner race & $20 \mathrm{~mm}$ \\
\hline Diameter of outer race & $47 \mathrm{~mm}$ \\
\hline
\end{tabular}

To understand how the bearing fault progresses with time it requires knowing each stage and the symptoms of these. Bearing defect frequencies (BDF) are exist only if the bearing is actually defective. In detection stage, frequency identifies the fault and location; harmonic content and amplitude indicate seriousness of fault. All defect frequencies should be identified early because at later stages of failure, the BDF may no longer be produced. Since amplitudes and harmonics of BDF are both important, it is not reliable only monitoring the amplitude level alone.

Vibration sensors used in the experiments are the piezoelectric type of accelerometers (see Table III for specifications).

TABLE III: SPECIFICATION OF ACCELEROMETER

\begin{tabular}{|l|l|}
\hline Brand & Metra Mess \\
\hline Type & KS80C \\
\hline Input Sensitivity & $100 \mathrm{mV} / \mathrm{g}$ \\
\hline Sensor Operating Voltage & $12-13.5 \mathrm{~V}$ \\
\hline Range of Constant Current & $2-20 \mathrm{~mA}$ \\
\hline Linear Frequency Interval & $0.7-10000 \mathrm{~Hz}$ \\
\hline
\end{tabular}

The detection of faults is performed by the Matlab based program, which provides the results of change in peak height and signal noise level. In the detection algorithm, the frequency and actual amplitude of peaks are determined by interpolation for a leaking spectrum. Difference between peak heights is used as the fault indicator component. It is scanned in the certain frequency bands (see Table IV).

TABLE IV: SIGNAL BANDS FOR APPROXIMATION AND DETAILS

\begin{tabular}{|c|c|c|c|}
\hline Approximations & Sub Bands (Hz) & Details & $\begin{array}{c}\text { Sub Bands of } \\
\text { Details (Hz) }\end{array}$ \\
\hline a1 & $0-1500$ & $\mathrm{~d} 1$ & $1500-3000$ \\
\hline $\mathrm{a} 2$ & $0-750$ & $\mathrm{~d} 2$ & $750-1500$ \\
\hline $\mathrm{a} 3$ & $0-375$ & $\mathrm{~d} 3$ & $375-750$ \\
\hline $\mathrm{a} 4$ & $0-187.5$ & $\mathrm{~d} 4$ & $187.5-375$ \\
\hline $\mathrm{a} 5$ & $0-93.75$ & $\mathrm{~d} 5$ & $93.75-187.5$ \\
\hline a6 & $0-46.88$ & $\mathrm{~d} 6$ & $46.88-93.75$ \\
\hline
\end{tabular}

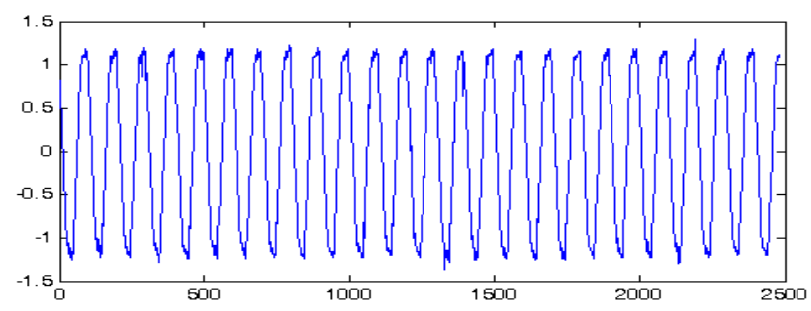

Fig. 3. Motor current signal in healthy bearing condition.

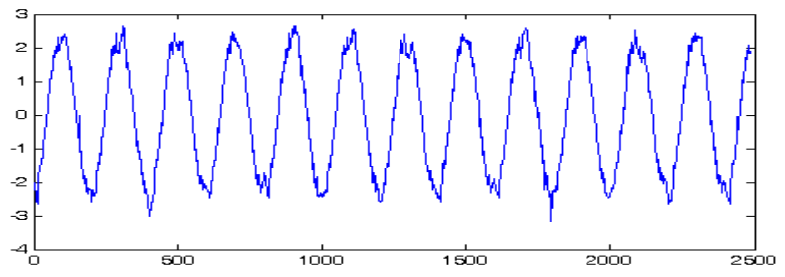

Fig. 4. Motor current signal in faulty bearing condition.

\section{EXPERIMENTAL RESULTS}

Here it is the experimental result for the bearing faulty motor. Single phase motor current signals in time domain are given sequentially in Fig. 3 and Fig. 4 for healthy and faulty bearing conditions. From there it is increment on high 
frequency content of the signal. It is also verified that the defect frequency harmonics are increasing with speed and bearing load. The influence of the fault on motor current is shown in Fig. 4.

Fig. 5 to Fig. 6 show the comparison of stator current spectrum of a four pole induction motor operating at no load. There is an increase on side bands of fundamental frequency.

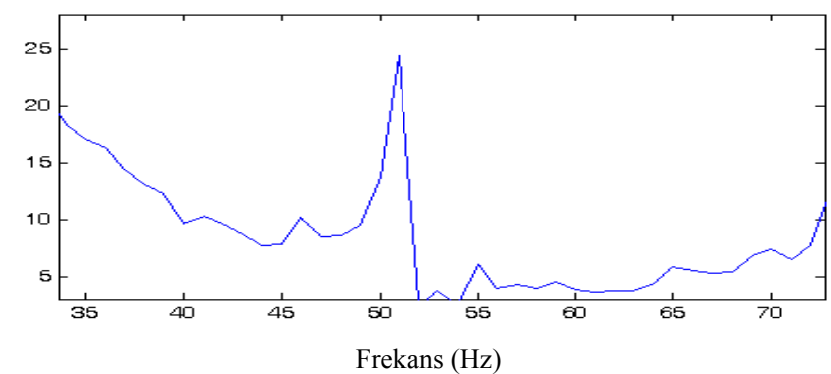

Fig. 5. Spectrum of motor current signal for the healthy bearing condition.

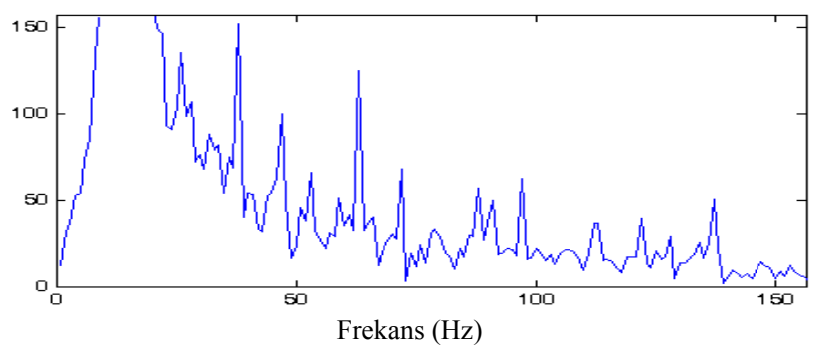

Fig. 6. Spectrum of motor current signal for the faulty bearing condition.

Each phase currents of motor imply same status in both healthy and faulty bearing cases. Thus, only to single phase current is used to apply discrete wavelet transform (DWT) and multi-resolution wavelet transform. It is seen an increase on the amplitude of the fundamental frequency of rotor speed.

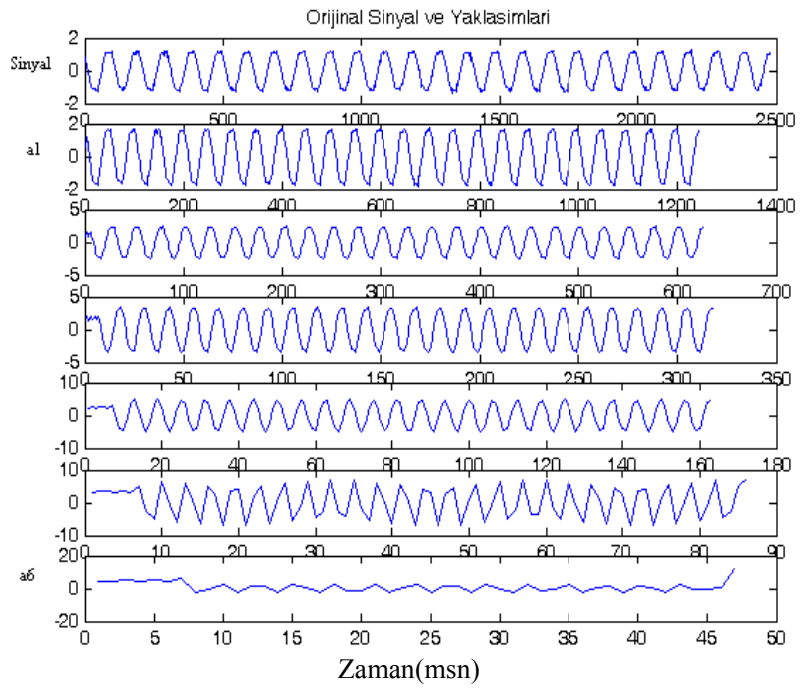

Fig. 7. Low frequency contents of motor current signal in healthy bearing condition

To detect fault DWT is applied to motor current signal for separation of signal components. As seen in Fig. 7 and in Fig. 8 motor current signals are decomposed to low and high frequency contents in six levels. Wavelet based analysis is used here as a comb filter to decompose signal. Wavelet transform is also combined with Fourier transform to enhance feature extraction capability. Approximations show slow dynamic variations like trend. The details are only implying fast dynamic variations.

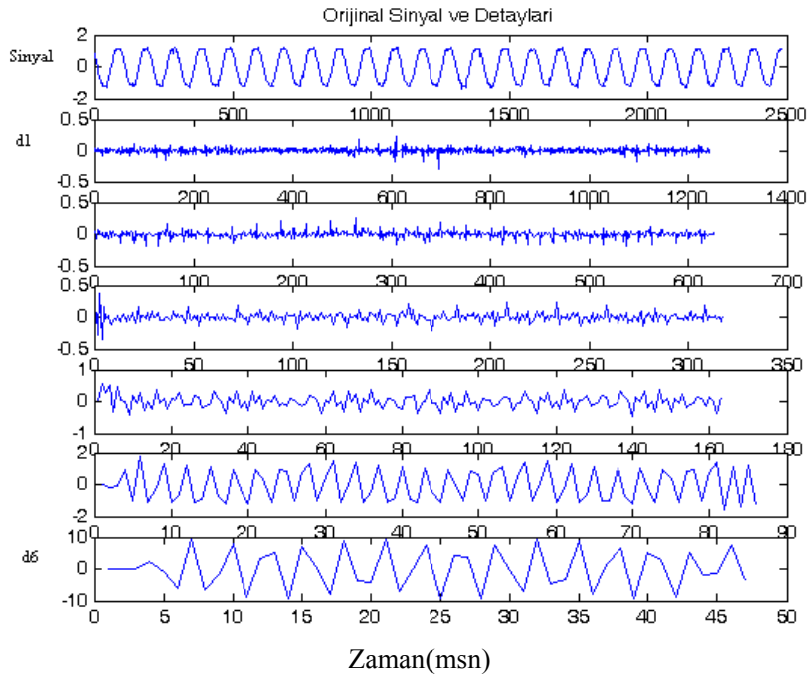

Fig. 8. High frequency contents of motor current signal in healthy bearing condition

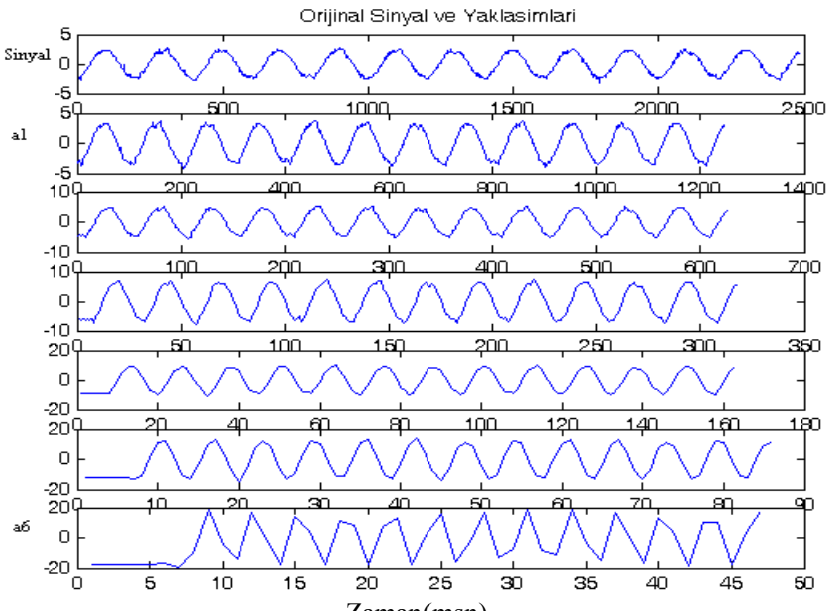

Fig. 9. Low frequency contents of motor current signal in faulty bearing condition.

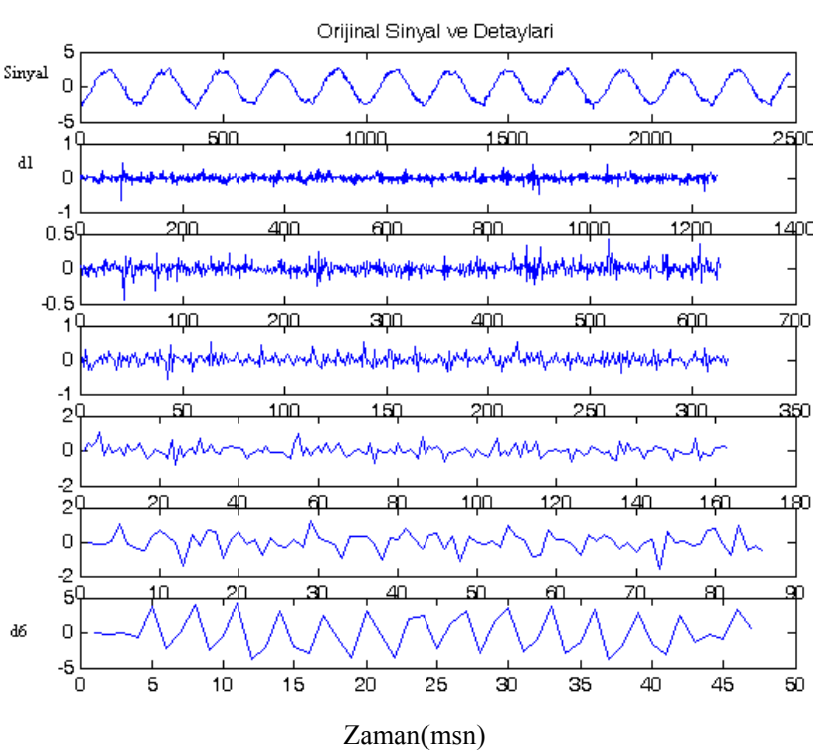

Fig. 10. High frequency contents of motor current signal in faulty bearing condition.

When Fig. 9 and Fig. 10 are compared in terms of high frequency components, there are increments in the 
amplitudes in $\mathrm{d} 1$ and $\mathrm{d} 2$ bands. It is also expected to see amplitude changes in the frequency of rotor speed due to the high force on the motor shaft.

It is noticed that the magnitudes of the eccentricity components $\left(f_{s} \pm k f_{r}\right)$ where $f_{s}, f_{r}$ and $k$ denote supply frequency, rotor rotation frequency and an index respectively increase as the fault level increases. However, the relationship between fault level and amplitude of eccentricity components are not linear. Therefore, it is not possible find a deterministic measure like the international standards

\section{CONCLUSIONS}

The common mechanical problems such as bearing failures in induction motor are investigated experimentally using motor current signal based on wavelet analysis technique. It should be noted from current spectrums that the predicted current components were small compare to large supply harmonics. Therefore it is important in the analysis to recognize those small changes. It is the key part of signal analysis in detection algorithm. However, it is required to do further study to predict the remaining life of the bearing. Wavelet transform has been successfully applied to motor current data to diagnose of bearing and other mechanical faults. Vibration signal analysis is required to assist detection.

\section{REFERENCES}

[1] R. R. Schoen, T. G. Habetler, F. Kamran, and R. G. Bartheld, "Motor bearing damage detection using stator current monitoring," IEEE Trans. on Industry Applications, vol. 31, no. 6, pp. 1274-1279, November/December 1995

[2] Z. Ye, A. Sadeghian, and B. Wu, "Mechanical fault diagnostics for induction motor with variable speed drives using adaptive neurofuzzy inference system," Electric Power System Research, vol. 76, pp. 742-752, June 2006.
[3] S. Seker and E. Ayaz, "Feature extraction related to bearing damage in electric motors by wavelet analysis," Journal of the Franklin Institute, vol. 340, pp. 125-134, March 2003.

[4] H. Douglas, P. Pillay, and A. K. Ziarani, "A new algorithm for transient motor current signature analysis using wavelets," IEEE Transactions on Industry Applications, vol. 40, no. 5, pp. 1361-1368, September/October 2004.

[5] L. Eren and M. J. Devaney, "Bearing damage detection via wavelet packet decomposition of the stator current," IEEE Instrumentation and Measurement Technology Conferences, vol. 53, pp. 431-436, April 2004.

[6] H. Bae, Y. T. Kim, S. H. Lee, S. Kim, and M. H. Lee, "Fault diagnostic of induction motors for equipment reliability and health maintenance based upon Fourier and wavelet analysis," Artificial Life Robotics, vol. 9, pp. 112-116, 2005.

[7] V. Purushotham, S. Narayanan, and A. H. P. Suryanarayana, "Multifault diagnosis of rolling bearing elements using wavelet analysis and hidden markov model based fault recognition," NDT\&E International, vol. 38, pp. 654-664, December 2005.

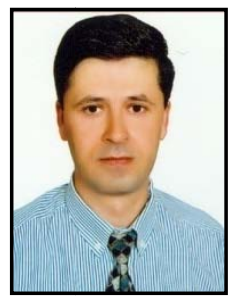

H. Çalıs graduated from Gazi University in 1986. He completed his M.Sc. degree in 1992 at the same university. He got his Ph.D. degree from the University of Sussex in 1998. He is now an associate professor at Suleyman Demirel University. He is interested in condition monitoring, signal analysis in electric machines.

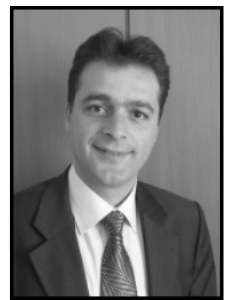

H. Fidan graduated from Marmara University in 1997. He completed his M.Sc. degree in 2006 at Suleyman Demirel University, and he continues his doctorate at the same university. 